\title{
O PAPEL DA DOGMÁTICA PENAL E DA SOCIOLOGIA JURÍDICA NA VIOLÊNCIA CONTRA A MULHER
}

\begin{abstract}
From the social juridical perspective and from theoretical categories such as power desproportion, domination, Criminal Dogmatics and public policy, this article questions the effective internalization of gender equality by those accused of violence against women. In order to do so, it presents data from an empirical research carried out in the Federal District about the perception of the Condemned about respect for women.
\end{abstract}

Keywords: Criminal Dogmatics; Law and Society; power desproportion; public policy; violence against women.

\section{Introdução}

A violência de gênero, especialmente a violência contra a mulher, tem sido objeto de inúmeras pesquisas quantitativas e qualitativas no âmbito das ciências sociais, da criminologia, das políticas públicas, dos direitos humanos. ${ }^{2}$ Estes estudos e a constante publicização de casos na mídia, articulada com a agenda do movimento feminista brasileiro, demonstram o quanto o tema ainda demanda atenção.

Neste sentido, a proposta do presente artigo é discutir a função da dogmática penal, da lei, a partir de um

\footnotetext{
1 Possui graduação em Direito pela Universidade de Brasília (1994), mestrado em Direito pela Universidade Metodista de Piracicaba (2001) e doutorado em Sociologia Política pela Universidade de Brasília (2007). PósDoutora pela Universidade da Califórnia/Davis (2014).Email: juliamximenes@ gmail.com

${ }^{2}$ Nos dados apresentados no Mapa da Violência 2015, tem-se que de 3,7 milhões de pessoas, com 18 anos ou mais, sofreram agressão de alguém conhecido. Já no relatório do Visível ao Invisível, tem-se, no que se refere às principais violências sofridas e quais os tipos de agressões são mais graves e frequentes nos últimos 12 meses anteriores à pesquisa, que a violência psicológica é preponderante entre as vítimas femininas e também masculinas, seguida pela violência física em ambos os casos. Nos dados do relatório, tem-se que para $73 \%$ da população brasileira a violência contra a mulher aumentou nos últimos 10 anos. Entre as mulheres, essa percepção eleva-se para $76 \%$ e, entre aquelas que foram vítimas de algum tipo de violência nos últimos 12 meses, para 79\%. Considerando a faixa etária, observa-se que a percepção de aumento prevalece para $76 \%$ ou mais das mulheres adultas e mais velhas (acima de 25 anos), enquanto entre as mais jovens (16 a 24 anos) encontra-se percepção um pouco maior de que a violência permaneceu a mesma (24\%). Não se observam grandes diferenças de percepção do aumento da violência segundo a renda e a escolaridade, sendo um pouco superior entre a população de baixa renda (até dois salários mínimos) e com menor escolaridade (75\% em ambos os grupos).
} 
olhar sociojurídico: em que medida a dogmática penal tem se isolado da sociologia jurídica ${ }^{3}$ na análise deste tipo de violência? Como romper com esse isolamento?

A partir de dados de uma pesquisa realizada no Distrito Federal em 2017, apresentaremos uma perspectiva de análise sociojurídica da questão: construir critérios metodológicos que possam ser empregados para descrever os papéis desempenhados pelo campo jurídico (Coutinho2013) na política pública de combate à violência contra a mulher. ${ }^{4} \mathrm{~A}$ proposta é problematizar a forma como o

\footnotetext{
${ }^{3}$ Andrade (2013) discute o papel da criminologia crítica no campo do ensino jurídico e salienta que a criminologia da violência estrutural "nos ensina a compreendê-los [crime, criminalidade e criminosos] não apenas a partir da mecânica do controle, mas funcionalmente relacionada às estruturas sociais (o capitalismo, o patriarcado, o racismo...) A seletividade do sistema penal é revelada, assim, como classista, sexista e racista, que expressa e reproduz as desigualdades, opressões e assimetrias sociais." (p. 182) A autora destaca o caráter periférico-ausente da Criminologia. Neste sentido o presente trabalho abordará a Criminologia Crítica na perspectiva da Sociologia Jurídica.

4 O autor prossegue: "[...] categorias ou ferramentas de análise pelas quais o direito pode ter seus papéis nas políticas públicas enxergados com algum ganho de clareza e nitidez. Por trás disso está a suposição de que se de fato é possível observar e compreender os papéis do direito nas políticas públicas, seria também possível, em tese, aperfeiçoá-los desde uma perspectiva jurídica." (p. 181/2)

${ }^{5}$ A expressão é de Garcia (2014) no contexto de uma pesquisa sobre direitos humanos mas que
}

92

Direito tem lidado com a efetivação da norma penal na perspectiva de "dessubstancializar"5 a categoria teórica "violência doméstica" para assim avaliar a função da lei penal.

Neste sentido, começaremos com a apresentação do campo teórico sociojurídico de investigação: a violência contra a mulher como violência interpessoal, marcada pela dissimetria de poder, em uma perspectiva cultural e costumeira, da rotina das pessoas.

Em seguida será apresentada a definição de Dogmática Penal e suas dificuldades diante da realidade social

por ser utilizada como referência de análise sobre o campo jurídico está próxima da proposta do presente artigo: "Em outras palavras, é importante manter aberta a possibilidade que a significação dos 'direitos humanos' possa variar não apenas no tempo e no espaço, mas também em função do observador que a observa e que a comunica (sistema político, sistema jurídico, sistema científico, etc.) . Assim, o medium 'direitos humanos' pode conter diferentes possibilidades de formas, as quais serão 'diferentemente' exploradas, dependendo do observador e do quadro de referência mobilizado para lhe atribuir um sentido. Deve-se assim revestir o conceito de direitos humanos, não como se fosse uma realidade ontológica, mas a partir de um ponto de observação específico, a partir de um sistema de referência." (grifos no original, p. 199) Para a autor o conceito de direitos humanos depende da função do sistema que os considera como tais, "políticos para o sistema político, jurídicos para o sistema jurídico"... Para nós esta noção é a dificuldade de compreensão sobre a função da pena no caso da violência contra a mulher e será objeto de reflexão no decorrer do artigo. 
complexa, para então adentrarmos nos resultados da pesquisa e a sua conexão de sentido com a proposta de leitura sociojurídica.

Esta leitura pressupõe uma compreensão construtivista da realidade: os atores sociais constroem a realidade social mediante suas práticas, os sujeitos não existem antes desta construção, a realidade é simbólica e discursiva (Villegas, 2010, p. 139) Isto se expressa na fala de um recente acusado de tentativa de feminicídio no Núcleo Bandeirante no Distrito Federal: "tenho o direito de agredir a minha mulher" ${ }^{6}$

O Direito estabelece a visão oficial, legítima e autorizada do mundo, contudo, é preciso articular análises que privilegiam a ação individual com elementos estruturais e esta é a proposta do presente artigo.

\section{Campo teórico sociojurídico}

A perspectiva sociojurídica apresentada neste artigo é da violência de gênero - violência interpessoal, marcada

\footnotetext{
${ }^{6}$ Frase que inicia uma reportagem especial de Alan Rios para o Correio Braziliense publicada no dia 12 de setembro de 2018 sobre seis vítimas de violência contra a mulher em duas horas em cinco regiões do Distrito Federal.

${ }^{7}$ As outras são: hegemonia do poder masculino, que permeia as relações entre homens e mulheres; a condição de subalternidade
}

pelas "dissimetrias de poder".

Afinal, é pela perspectiva de gênero que se entende o fato de a violência contra as mulheres emergir da questão da alteridade, enquanto fundamento distinto de outras violências. Ou seja, esse tipo de violência não se refere a atitudes e pensamentos de aniquilação do outro, que venha a ser uma pessoa considerada igual ou que é vista nas mesmas condições de existência e valor que o seu perpetrador. Pelo contrário, tal violência ocorre motivada pelas expressões de desigualdades baseadas na condição de sexo, a qual começa no universo familiar, onde as relações de gênero se constituem no protótipo de relações hierárquicas. (Bandeira, 2014, p. 450)

Bandeira (2014) aponta algumas linhas de indagações sobre a violência de gênero nas ciências sociais e nos concentraremos na presença das dissimetrias das normas e regras sociais em relação aos comportamentos de homens e mulheres. ${ }^{7}$ Isto porque "as relações violentas existem porque as relações assimétricas de poder permeiam a vida rotineira das pessoas". (p. 451)

Logo, não há ruptura significativa nas estruturas antigas, as que ordenam e regem as hierarquias e os papéis femininos e masculinos

feminina, baseada na hierarquia de gênero; a reprodução das imagens de homem e mulher e dos papéis a ambos atribuídos por meio da construção social da violência; a existência disseminada e, ao mesmo tempo, invisibilizada das violências nas relações familiares e sociais. (p. 455) 
na esfera familiar. Isto é, as concepções dominantes de feminilidade e masculinidade ainda se organizam a partir de disputas simbólicas e materiais, que operam no interior dos espaços domésticos e que, por conseguinte, acabam por se projetas a outras searas, sendo processadas em outros espaços institucionais. (Bandeira, 2014, p. 457)

Por isso, compreender as múltiplas faces da violência de gênero perpassa a própria função do Direito. $\mathrm{O}$ patriarcado e a dominação masculina, isoladamente, não são causas suficientes para explicar a violência contra a mulher (Bandeira, 214, p. 457), inclusive diante das tensões entre público/privado presentes nestes conflitos interpessoais. Aqui começa a análise do próprio campo jurídico.

Considerando a interpretação de Bourdieu (1989) ${ }^{8}$ temos que o campo jurídico é um espaço de luta pela última manifestação sobre "dizer o que é o direito":

O campo jurídico é o lugar de concorrência pelo monopólio do direito de dizer o direito, quer dizer, a boa distribuição (nomos)

8 Os estudos de Pierre Bourdieu tratam basicamente das relações humanas como relações de poder, que reproduzem um sistema objetivo de dominação interiorizado enquanto subjetividade. A reprodução desta lógica de dominação não se restringe apenas às instituições estatais mas se inscreve também em níveis mais profundos, atingindo representações sociais de diversos campos como político, educacional, ou a boa ordem, na qual se defrontam agentes investidos de competência ao mesmo tempo social e técnica que consiste essencialmente na capacidade reconhecida de interpretar (de maneira mais ou menos livre ou autorizada) um corpus de textos que consagram a visão legítima, justa, do mundo social (p. 212).

Neste sentido, a cultura jurídica, seja do campo jurídico seja do campo social, é um conjunto complexo de discursos e marcos simbólicos mediante os quais os indivíduos dão significado a suas atividades legais; disposições internalizadas por meio de socialização, de esquemas de percepção e compreensão do mundo, mas que de alguma forma representam uma ordem hierárquica. (Villegas, 2010, p. 154-158)

Por isso acompanhamos Villegas (2010) quando reflete sobre os Estudos de Consciência Jurídica - ECJ, movimento que surgiu no final da década de 80 dentro do Law and Society americano. A proposta do ECJ é investigar os sujeitos.

We seek access to the meaning of law in the lives of ordinary citizens

artístico e linguístico. (Ortiz, 1983) Neste sentido a sua relevância para o campo jurídico e para a presente pesquisa: suas reflexões sobre as relações de poder envolvidas nas diferenças e desigualdades sociais, que podem acarretar ferramentas legais que busquem diminuir as relações de dominação. (Bourdieu, 1989; 1990; 1996; 2002; 2003) 
- the ways in which commonplace transactions and relationships come to assume or not to assume a legal character, and the ways in which the shape of everyday life is informed by law. Studies of legal culture and conscious- ness attempt to address these questions about the place and meaning of law in the lives of ordinary citizens. (Ewick; Silbey, 1992, p. 738)

Para as autoras o objetivo é compreender o papel do Direito nas relações sociais relativizando o papel da estrutura $^{9}$, o que para Villegas (2010) é um equívoco: ao isolar a consciência jurídica, o ECJ subestima o papel da dominação na análise. "En términos sociojurídicos, seríia cuestión de combinar la visión simbólica del derecho... con una teoría de la estratégia simbólica, entendida como un

9 "Cultural-constitutive analyses begin by rejecting, I believe, the dichotomy between agency and structure that is reproduced in the effort to specify mechanisms of accumulation or points of condensation. Treating consciousness as historical and situational, cultural analyses also shift attention to the constitution and operation of social structure in historically specific situations rather than macrosociological, transhistorical processes. These analyses reject the dualisms implied by recurrent debates about the relative role of structure and agency in shaping the work and focus instead on the role of consciousness in (re)producing the social world." (SILBEY, 1992, p. 47)

10 Apenas após ter dessubstancializado o conceito é que pudemos sair da confusão que o cerca, podendo observá-lo de um ponto de vista empírico. Foi necessário separar o conceito de sua 'substância', destacá-lo das formas e dos conteúdos com os quais estamos habituados a justapô-lo[...]. A dessubstancialização das instrumento político, sea ésse de dominación o de emancipación social". (p. 169)

Portanto, a análise dos dados sobre respeito por parte dos apenados na pesquisa que será objeto adiante permitirá uma "dessubstancialização"10 do conceito de violência de gênero a partir de três campos: o social, o jurídico e o político (especificamente da política pública). Esta análise permitirá observar a função do Direito nos objetivos perseguidos pelas políticas públicas que provocaram a Lei Maria da Penha ${ }^{11}$.

Além disso, a discussão sobre os efeitos de leis e de políticas públicas privilegia, entre nós, enfoques e abordagens predominantemente estruturais (em oposição a funcionais), que tendem a ser estáticos, formais ou procedimentais. Exemplos disso

categorias jurídicas aparece assim como uma condição de possibilidade para a observação do direito de um ponto de vista externo. Ela nos obriga a criar uma distância com relação às categorias jurídicas produzidas pelo ponto de vista interno, pois trata-se do único modo de 'controlar' a qualidade da observação e sua “independência'" (Garcia, 2014, p. 201/2)

11 A Lei Maria da Penha, Lei 11.340/2006, pode ser considerada um paradigma à proteção da mulher. Para Ribeiro (2013), a Lei tem como objetivo resguardar e amparar a mulher contra todo tipo de violência, seja de natureza física, psicológica, sexual, patrimonial e moral. A Lei ainda prevê diversos instrumentos para o combate à violência contra a mulher, desde as sanções penais, mas também sanções com aspectos administrativos, civil, penal e trabalhista. Prevê ainda o aumento da pena, prisão em flagrante e preventiva para o agressor, a determinação de medidas protetivas. 
são controvérsias e disputas de interpretação envolvendo a observância de regras de competência, a autonomia de órgãos e entes públicos, a legalidade dos atos praticados por autoridades administrativas e as possibilidades e limites da revisão de decisões de política pública pelo Judiciário. (Coutinho, 2013, p. 183$)^{12}$

Os fins das políticas públicas podem ser objeto de análise sob dois ângulos: como produto de escolhas políticas (campo político) onde o Direito é instrumental, eminentemente realiza essas escolhas; e como fonte definidora dos próprios objetivos aos quais serve como meio (Coutinho, 2013, p. 194). A análise aqui proposta não exclui as duas abordagens, pelo contrário, busca definir uma “espécie de 'mapa' de responsabilidades e tarefas nas políticas públicas" (Coutinho, 2013, p. 196) atribuída ao Direito. Por isso o enfoque na função da pena, que será analisada no próximo item.

As normas jurídicas dão lugar a múltiplas práticas sociais, e a presente pesquisa busca justamente refletir sobre a função da dogmática penal sob um

$12 \mathrm{O}$ autor trabalha com quarto ideias-chave: "Confrontado com o intrincado desafio de observar e descrever as políticas públicas desde um ponto de vista jurídico, proponho e descrevo, a seguir, alguns papéis e tarefas para o direito e seus operadores em políticas públicas. Esses papéis consistem em apontar fins e situar as
96

olhar sociojurídico. Quando o apenado responde se respeita a mulher, o que isso significa? O "Ser” mulher está carregado de sentidos: ser esposa, filha, mãe, cuidadora, entre os compromissos de ser fiel, companheira, amiga, boa mãe.... (Bandeira, 2014). É possível relacionar este "ser" com as funções do Direito na política pública?

Enquanto categoria elaborada pelo feminismo, depois agregada à academia, a perspectiva de gênero, intrinsecamente, carrega em si a politicidade e o compromisso com as transformações sociais relacionadas às mulheres, assim como um novo olhar sobre as relações de poder estabelecidas entre mulheres e homens, homens e homens e mulheres e mulheres. (Godoy, 2011, p. 29)

Portanto, problematizar a violência de gênero a partir da função da dogmática penal expressa na Lei Maria da Penha demanda explicar e compreender a violência contra a mulher a partir da lógica da hierarquia de poderes presente na sociedade: "a mulher sempre ocupou posição social inferior, sofrendo injustiça social, em virtude das desigualdades construídas e

políticas no ordenamento (direito como objetivo), criar condições de participação (direito como vocalizador de demandas), oferecer meios (direito como ferramenta) e estruturar arranjos complexos que tornem eficazes essas políticas (direito como arranjo institucional)". (p. 193/4) 
naturalizadas historicamente" (Godoy, 2011, p. 6)

Neste sentido a proposta inicial de "dessubstancialização" da violência de gênero, pois a compreensão dos dados exige um olhar que depende do campo.

\section{Campo jurídico e função da pena}

A partir de Andrade (2013) sobre a relação entre Criminologia e Dogmática Penal, abordaremos agora um entrave na reflexão sobre a função da lei no contexto da violência de gênero, que é o próprio papel da dogmática enquanto ordem vigente.

Ensinar criminologias, nesta perspectiva, é concorrer para a formação de uma consciência jurídica crítica responsável, capaz de transgredir as fronteiras, sempre generosas, do sono dogmático, da zona de conforto do penalismo adormecido na labuta técnico-jurídica; capaz de inventar novos caminhos para o enfrentamento das violências (individual, institucional e estrutural) e esse talvez seja o melhor tributo que possam prestar ao Ensino e à formação profissional-cidadã. (p. 183)

Contudo, não será através da Dogmática Penal que "a mulher encontrará a proteção e a igualdade, pois a mudança de comportamento e de mentalidade vem através da educação e de ações preventivas" (Mello, 2010, p. 946).

Neste sentido a crítica de Ferraz sobre a dogmática e a necessidade de incluir outros saberes na análise do fenômeno jurídico:

\begin{abstract}
Uma disciplina pode ser definida como dogmática à medida que considera certas premissas, em si e por si arbitrárias (isto é, resultantes de uma decisão), como vinculantes para o estudo, renunciando-se, assim, ao postulado da pesquisa independente. Ao contrário das disciplinas zetéticas, cujas questões são infinitas, as dogmáticas tratam de questões finitas. (2008, p. 24/5)
\end{abstract}

No Direito, os juristas procuram compreender o fenômeno jurídico nos marcos da ordem vigente, como uma limitação para a sua atuação, controlando as "incertezas" (Ferraz, 2008). Apesar da relevância da lei, ela não acaba com as incertezas, pois o fenômeno jurídico é também um fenômeno social, repleto de complexidades.

Nem sempre é absoluta, coerente e linear a relação que existe entre a norma positiva, a norma aplicada aos casos e os valores presentes na sociedade. Fica patente que o momento da aplicação do Direito é muito mais do que o momento de uma mecânica subsunção do fato à norma positiva jurídica. É o momento supremo do Direito em que ressaltam muito mais os valores do que fatos sociais. Contudo, os valores sociais, por vezes travestidos em estereótipos e preconceitos discriminatórios, atuam sub-repticiamente, 
inconscientemente

nas argumentações dos operadores do Direito, impedindo-os de desempenharem suas funções tendo em vista o respeito, a dignidade e a justiça. (Pimentel; Schritzmeyer; Pandjiarjian, 1998, p. 65)

\section{Conforme será apontado}

adiante, os resultados da pesquisa demandam uma observação a partir de um ponto de vista multidisciplinar, evitando a dimensão normativa do dever-ser ${ }^{13}$ e a crença ingênua de que a ordem vigente pode transformar a realidade. Esta é na verdade uma das grandes contribuições da Sociologia Jurídica - o olhar externo para a defasagem entre o plano formal e o real, entre o dever-ser e o ser. (Azevedo, 2005)

\section{A pesquisa ANVERSO}

O presente estudo foi realizado

\footnotetext{
13 'Para criar as condições de 'escuta' entre o Direito as Ciências Sociais e a possibilidade de que o diálogo seja verdadeiramente um, devemos aprender a complexificar e a olhar de maneira mais crítica, não exclusivamente as insuficiências do olhar interno, mas também os pontos cegos que caracterizam frequentemente o olhar externo". (Garcia, 2014, p. 204)

14 RESOLUÇÃO N. 15/2015 - TRIBUNAL PLENO DO TJDFT. Art. $2^{\circ}$ Compete à Vara de Execuções das Penas em Regime Aberto VEPERA:

I - a execução de penas restritivas de liberdade em regime aberto provenientes de sentença
}

a partir da coleta de dados primários, no escopo de uma pesquisa quantitativa, com aplicação de questionários. Os entrevistados foram apenados nas audiências de sursis e prisão domiciliar semanais na Vepera, tendo sido entrevistados todos os apenados que compareceram às audiências nas sextasfeiras no período de 10/02/2017 a 24/03/2017.

Pela natureza da pesquisa e da dificuldade de controle das audiências e os crimes correlatos da Lei Maria da Penha, não há possibilidade de influência e controle das variáveis, o que caracteriza esta pesquisa como correlacional.

O universo foram os apenados da Lei Maria da Penha que se apresentaram em audiência na Vepera ${ }^{14}$, de todas as classes sociais com mais de 18 anos. A técnica de pesquisa utilizada foi quantitativa de entrevista individual

penal condenatória, da suspensão condicional da pena e o regime aberto em prisão domiciliar e livramento condicional;

II - fixar as condições do regime aberto em prisão domiciliar;

III - colaborar com a Vara de Execuções Penais na descentralização de suas atividades; IV - decidir pedidos de unificação das penas nas hipóteses previstas no inciso I;

$\mathrm{V}$ - inspecionar os estabelecimentos onde se efetive o cumprimento de penas restritivas de liberdade em regime aberto provenientes de sentença penal condenatória. 
com apenados em condições de sursis da pena ou início do cumprimento da pena em prisão domiciliar, não foram entrevistados apenados provenientes da progressão de regime. A abrangência da pesquisa foi apenas na Vepera do Tribunal de Justiça do Distrito Federal (TJDFT). A amostra total foi de 60 questionários.

$\mathrm{O}$ procedimento adotado para a coleta dos dados foi o de aplicação de questionários estruturados com perguntas fechadas, com entrevista que tinha duração média de 15 a 20 minutos, nos meses de fevereiro e março de 2017, num total de cerca de oito semanas de aplicação de questionários e uma semana de aplicação de questionário teste (Anexo C). Os entrevistadores foram em maior parte mulheres, o critério de gênero do entrevistador não será computado para separação da amostra de dados coletados, por não representar uma parcela significativa e pela natureza da amostra.

A ferramenta de análise é um questionário estruturado que é composto por cinco partes principais, perfil geral/socioeconômico, relação e regime de união com a mulher que consta no processo, questões secundárias, sobre o cumprimento da pena e a percepção/autoavaliação do apenado. $\mathrm{O}$ total é de 24 questões nas primeiras quatro partes e 20 itens na parte correspondente à autoavaliação.

$\mathrm{Na}$ aplicação de teste para a validação do instrumento de pesquisa, que foi feita com quatro apenados, foi verificada a necessidade de ajuste do instrumento de pesquisa. Os principais fatores que indicaram a necessidade de aperfeiçoamento foram a dificuldade de leitura dos apenados, a dificuldade de entendimento das questões, o que levou a adoção da aplicação por meio de entrevistas. Nas quais os entrevistadores podem explicar as situações.

Entre as dificuldades enfrentadas no primeiro instrumento de pesquisa houve uma negação dos apenados quanto ao fato de serem chamados de réu, ou mesmo se citada a palavra crime. Outra pergunta que precisou ser remodelada era a que tratava sobre quando as agressões começaram. Foi substituída a palavra agressão por problemas. Qualquer menção à agressão era veementemente negada. A pergunta sobre o maior medo na relação anterior também foi substituída, pois há a negação do medo em qualquer relação. Foi então substituída para o que você não gostaria que ela fizesse no 
relacionamento. A pergunta que questionava sobre o motivo das agressões foi abrandada para qual foi o motivo da situação que está narrada no processo.

Qualquer um destes termos ensejou um grande número de escusas de que houvesse sido cometido um crime ou que se tivesse feito alguma coisa. Com a presença destas afirmativas, a aplicação do questionário se estendia longamente com a presença de um desabafo do apenado sobre o fato de não ter cometido crime algum. Assim, diante da total negação de envolvimento, o preenchimento do questionário restavase prejudicado, o que inviabilizaria a aplicação da pesquisa. Observando estes requisitos, foi feito um ajuste no questionário de teste e definido o questionário final (Anexo A) a ser aplicado.

Destacamos o caminho percorrido para definição dos termos no questionário porque ele, por si só, já demonstra a dificuldade na categorização da violência de gênero por parte do apenado conforme salientaremos adiante.

Uma das áreas contempladas pela pesquisa trata do relacionamento com a mulher que ocasionou a ação penal,
100

o que para os apenados é conhecido como o processo em questão. A percepção do homem a respeito das dificuldades enfrentadas no relacionamento: falta de respeito (cuidado, consideração, medo, não atender as ordens do marido) falta de diálogo (comunicação), excesso de ciúmes (desconfiança), falta de carinho (carícia/contato, toque), falta de empatia (capacidade psicológica de colocar-se no lugar do outro) foi destacada para o presente artigo. Também foi observada a expectativa do homem em relação ao comportamento feminino e do não cumprimento de possibilidades como: abandonar, trair, ter maior sucesso profissional, ser trocado por outro.

$\mathrm{Na}$ segunda parte do questionário considerada para o presente artigo, há informações sobre o marco do distúrbio/crise do relacionamento conjugal, quando e em qual situação/momento houve o início da violência, que passou-se a denominar problemas. Também foi abordado o motivo da situação relatada no processo, tendo o comportamento da mulher como causa (a mulher fez por merecer, ela te desobedeceu, ela te pressionou, ela te traiu, ela tem ciúmes); comportamento do homem como causa (tenho ciúmes dela e não confio nela); dificuldades 
como falta de diálogo e falta de respeito; sem motivo aparente (porque eu tive vontade).

Para o tratamento estatístico dos dados foi criada uma máscara específica para o recebimento dos dados no questionário, digitados utilizando um formulário desenvolvido propriamente para o trabalho no Google Docs. O objetivo deste método é facilitar a organização da informação e gerar resultados fidedignos e precisos acerca dos questionários aplicados.

Dificuldades enfrentadas no relacionamento e comportamento esperado da parceira

\begin{tabular}{|c|c|c|c|}
\hline & & Frequência & $\begin{array}{l}\text { Porcentual } \\
(\%)\end{array}$ \\
\hline de ciúmes & Excesso & 10 & 18,2 \\
\hline carinho & Falta de & 1 & 1,8 \\
\hline diálogo & Falta de & 11 & 20,0 \\
\hline empatia & Falta de & 9 & 16,4 \\
\hline respeito & Falta de & 20 & 36,4 \\
\hline & NR & 4 & 7,3 \\
\hline & Total & 55 & 100,0 \\
\hline
\end{tabular}

Tabela 1 - Frequência das maiores dificuldades enfrentadas no relacionamento.

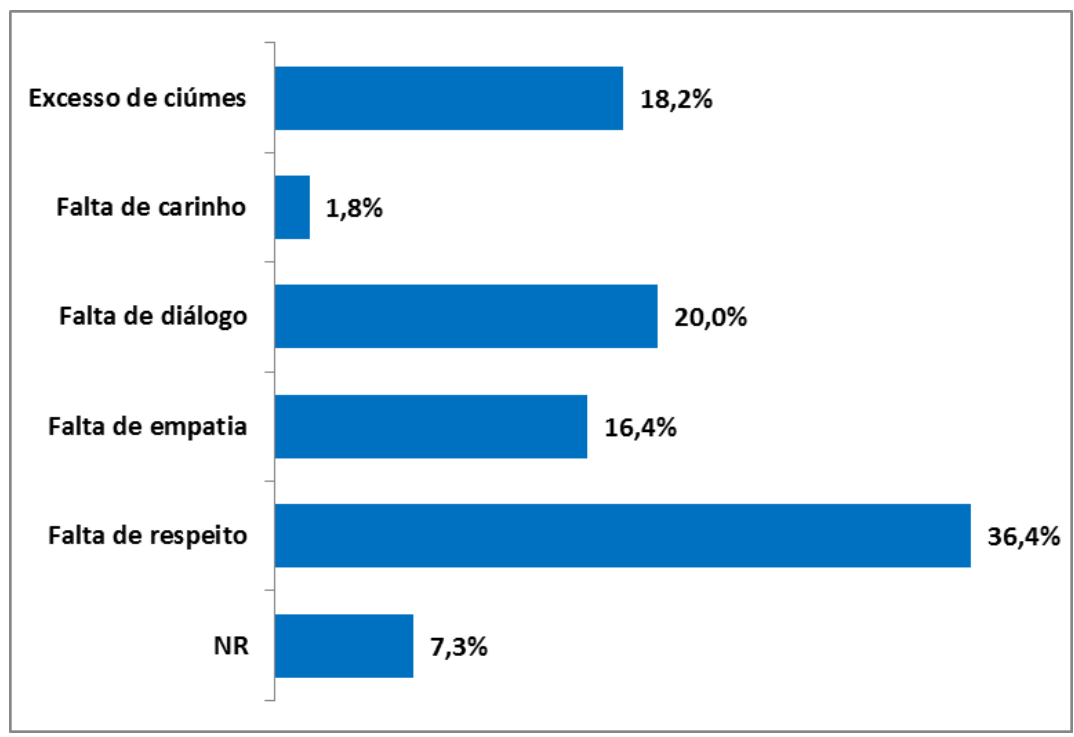

Gráfico 1 - Distribuição das dificuldades enfrentadas no relacionamento. 


\section{Quanto às dificuldades}

enfrentadas no relacionamento e $\mathrm{o}$ comportamento esperado da parceira, temos que a maior dificuldade enfrentada no relacionamento é a falta de respeito, presente em $36,4 \%$ das relações, seguida pela falta de diálogo, que representa $20 \%$, e o excesso de ciúmes, que representa 18,2\% dos problemas. Ao mesmo tempo, tem-se que o maior medo dos homens no relacionamento é a traição, 32,7\%. Já a troca e o abandono representam, juntos, $23,6 \%$ dos casos.

Neste conjunto de dados, pode-se analisar que os homens acreditam, em grande parte, que as parceiras devem respeito a eles: não controlar, não discordar, não invadir o espaço alheio podem ser atitudes relacionadas à falta de respeito. A falta de diálogo pode ser entendida como uma dificuldade de comunicação entre os parceiros, o que culmina em atos de violência para a legitimação do controle e do poderio do parceiro na relação.

A ideia de posse e controle está intimamente relacionada com a questão da traição, no que chamamos anteriormente de "dissimetrias de poder". Quanto ao comportamento não esperado da parceira, a maioria dos entrevistados não respondeu esta questão por acreditar que não tem medo de nenhum comportamento da parceira, o que corresponde a $29,1 \%$ do quantitativo. Embora quase $1 / 3$ dos homens dissessem isso, há uma clara dificuldade em aceitar qualquer um dos fatores como abandono ou traição por parte dos mesmos.

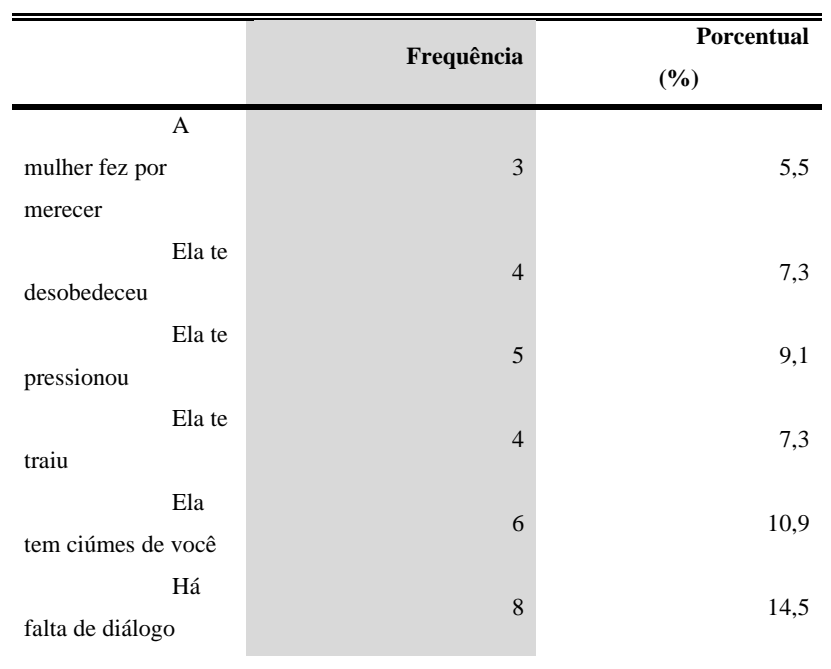




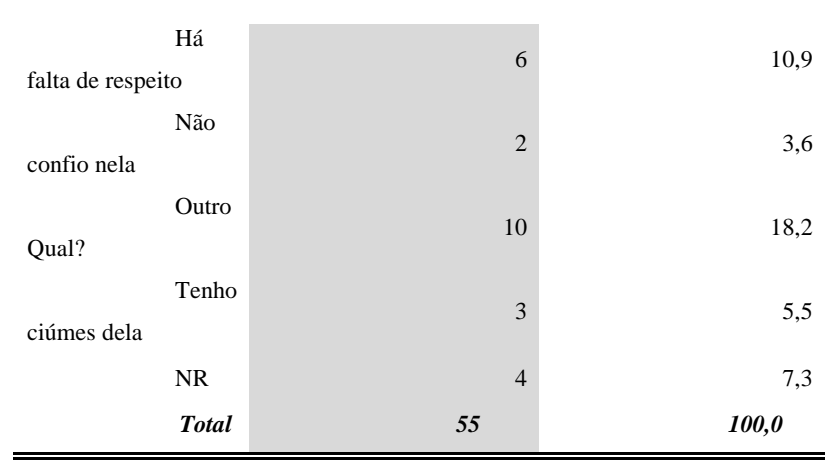

Tabela 2 - Frequência de situações desencadeantes de violência doméstica.

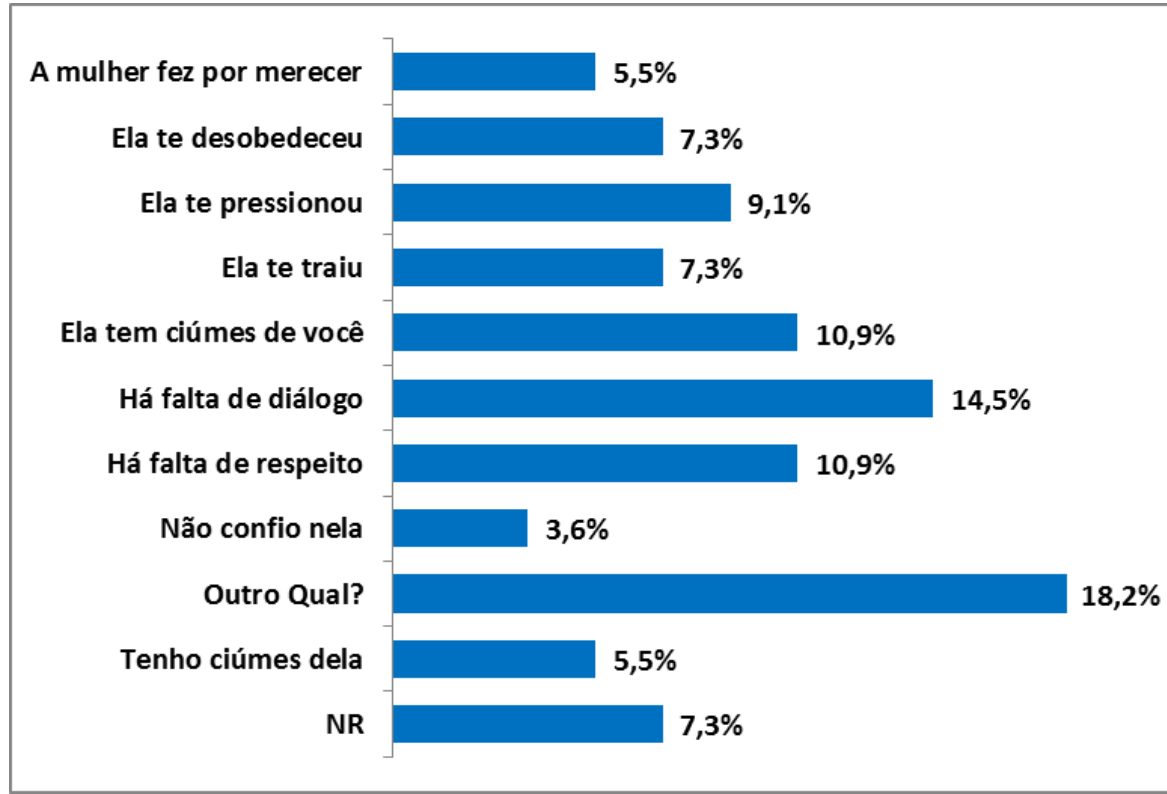

Gráfico 2 - Distribuição das situações desencadeantes da violência doméstica.

Quanto ao marco temporal de início da violência doméstica, pode-se observar que ela pode surgir no início ou no final do relacionamento. Baseado na verbalização das entrevistas, há um momento desencadeante para o ápice da violência física, como um novo emprego, mudança de cidade, novos amigos. São situações que podem representar a perda do poder de controle sobre a vítima. Pode-se encontrar relatos nos questionários de pesquisa que vão desde a falta de motivo até a influência de terceiros.

Quanto às situações desencadeadoras da violência doméstica, surge novamente a falta de diálogo como um dos principais desencadeadores da violência doméstica, com 14,5\%, seguido de ciúmes e falta de respeito, variáveis já examinadas na questão relativa às dificuldades enfrentadas no relacionamento. Se somadas, as variáveis relativas ao comportamento da parceira (a mulher fez por merecer, ela te 


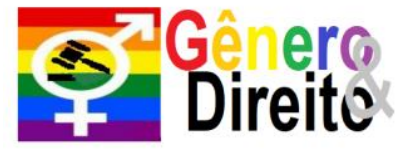

Periódico do Núcleo de Estudos e Pesquisas sobre Gênero e Direito

Centro de Ciências Jurídicas - Universidade Federal da Paraíba

V. 9 - $\mathrm{N}^{\circ} 02$ - Ano 2020 desobedeceu, ela te pressionou, ela te traiu, ela tem ciúmes de você) representam 40,1\%, ou seja, pode ser percebido que há uma culpa da vítima por ter sofrido violência doméstica.

Definição do apenado sobre o que é ser homem

\begin{tabular}{|c|c|c|}
\hline & Frequência & $\begin{array}{l}\text { Porcentual } \\
(\%)\end{array}$ \\
\hline $\begin{array}{ll} & \text { Ser } \\
\text { educado } & \end{array}$ & 16 & 29,1 \\
\hline $\begin{array}{l}\text { Ser } \\
\text { educado; Ser } \\
\text { respeitador }\end{array}$ & 3 & 5,5 \\
\hline $\begin{array}{l}\text { Ser } \\
\text { educado; Ser } \\
\text { respeitador; Outro }\end{array}$ & 1 & 1,8 \\
\hline $\begin{array}{ll} & \text { Ser } \\
\text { respeitador } & \end{array}$ & 27 & 49,1 \\
\hline (s)? Qual $\quad$ Outro & 3 & 5,5 \\
\hline NR & 5 & 9,1 \\
\hline Total & 55 & 100,0 \\
\hline
\end{tabular}

Tabela 3 - Frequência dos comportamentos definidores da masculinidade sob o ponto de vista dos apenados.

\begin{tabular}{|c|c|c|c|}
\hline & & Frequência & $\begin{array}{l}\text { Porcentual } \\
(\%)\end{array}$ \\
\hline & Bom e fiel & 1 & 25,0 \\
\hline & Humildade & 1 & 25,0 \\
\hline & Inteligente & 1 & 25,0 \\
\hline & Ser & 1 & 25,0 \\
\hline & Total & 4 & 100,0 \\
\hline
\end{tabular}

Tabela 4 - Frequência de outros comportamentos que definem a masculinidade sob o ponto de vista dos apenados. 


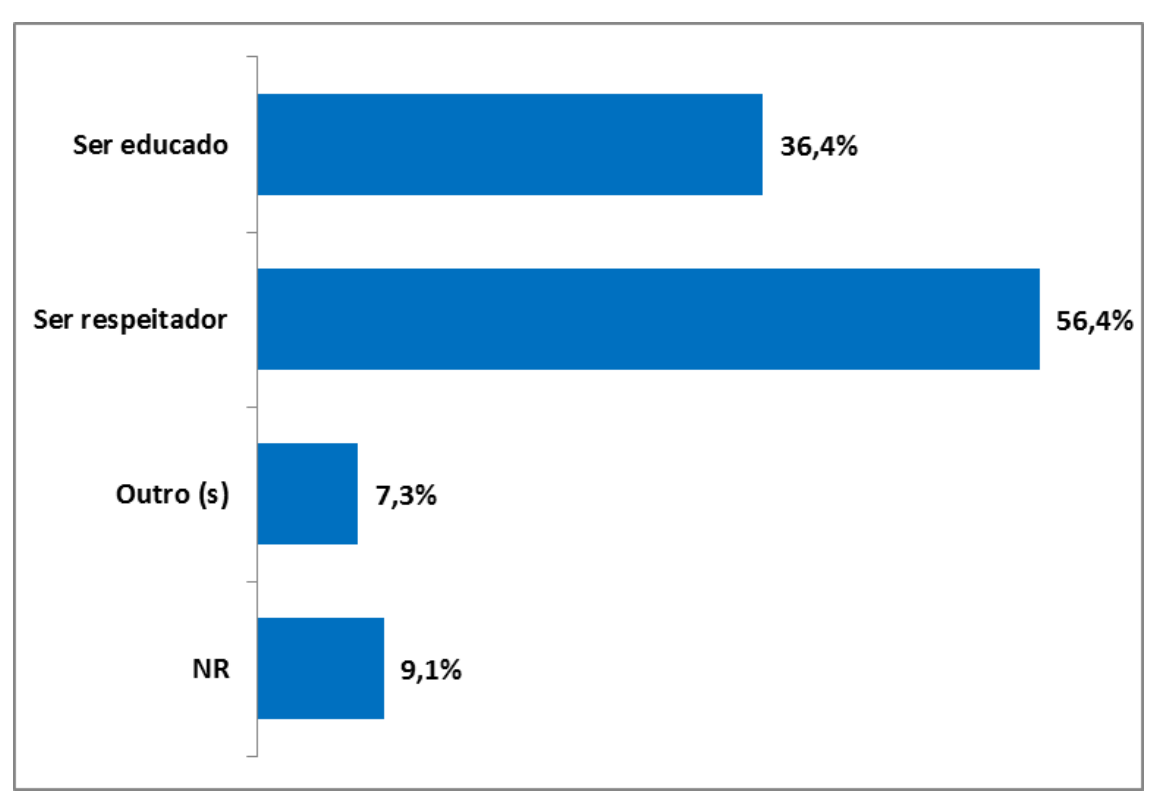

Gráfico 3 - Distribuição dos comportamentos que definem a masculinidade sob o ponto de vista dos apenados.

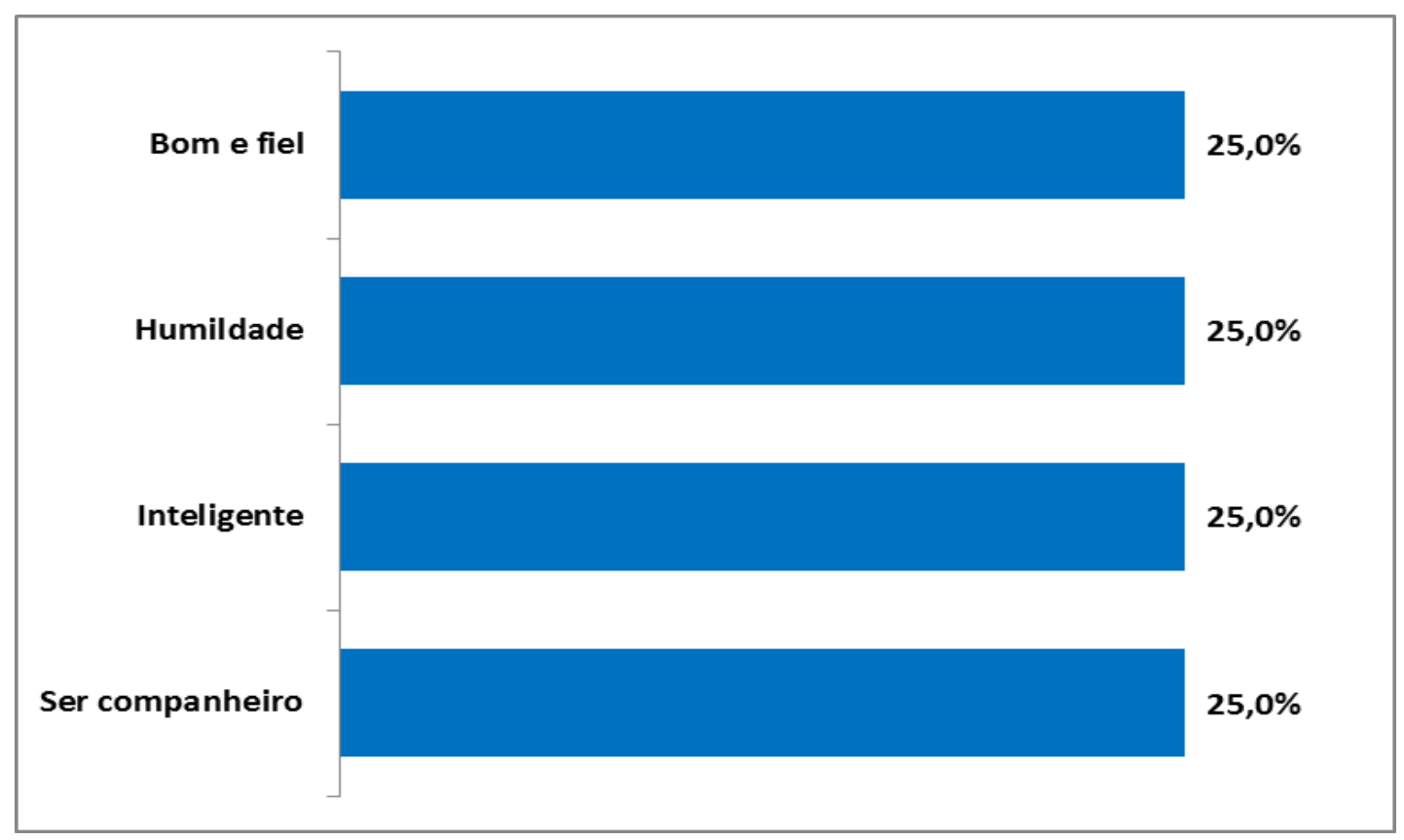

Gráfico 4 - Distribuição de outros comportamentos que definem a masculinidade sob o ponto de vista dos apenados.

Pode-se observar que ser respeitador é responsável por $56,4 \%$ das respostas que definem um homem, e entre outros foram citados bom e fiel, humilde, inteligente e companheiro com menor frequência. É possível relacionar a definição de homem com respeitador.

Aqui, abre-se um espaço para a discussão do conceito de respeitador, que pode ser desde o respeito à intimidade e 
privacidade da parceira como o fato de ser respeitador aquele que não força intimidades sexuais diretas com sua parceira, não a tratando como objeto. Assim, parece haver uma forte presença cultural do que significa respeito para o homem, o que não está relacionado diretamente com a prática de violência
106

doméstica, criando uma relação diferenciada, a "dissimetria" de poder que provocou o ato violento.

Afirmativa: É preciso respeitar as mulheres em escala de avaliação variando de concordo totalmente a descordo totalmente

\begin{tabular}{llrr}
\hline \hline & & Frequência & \multicolumn{2}{c}{ Porcentual } \\
& & 4 & 7,3 \\
parcialmente & Concordo & & \\
& Concordo & 43 & 78,2 \\
totalmente & & 1 & 1,8 \\
& Discordo & & \\
parcialmente & & 1 & 1,8 \\
totalmente & Discordo & 2 & 3,6 \\
& Indiferente & 4 & 7,3 \\
& NR & & 100,0 \\
\hline \hline
\end{tabular}

Tabela 5 - Frequência da avaliação da percepção dos apenados sobre a necessidade de respeito às mulheres. 


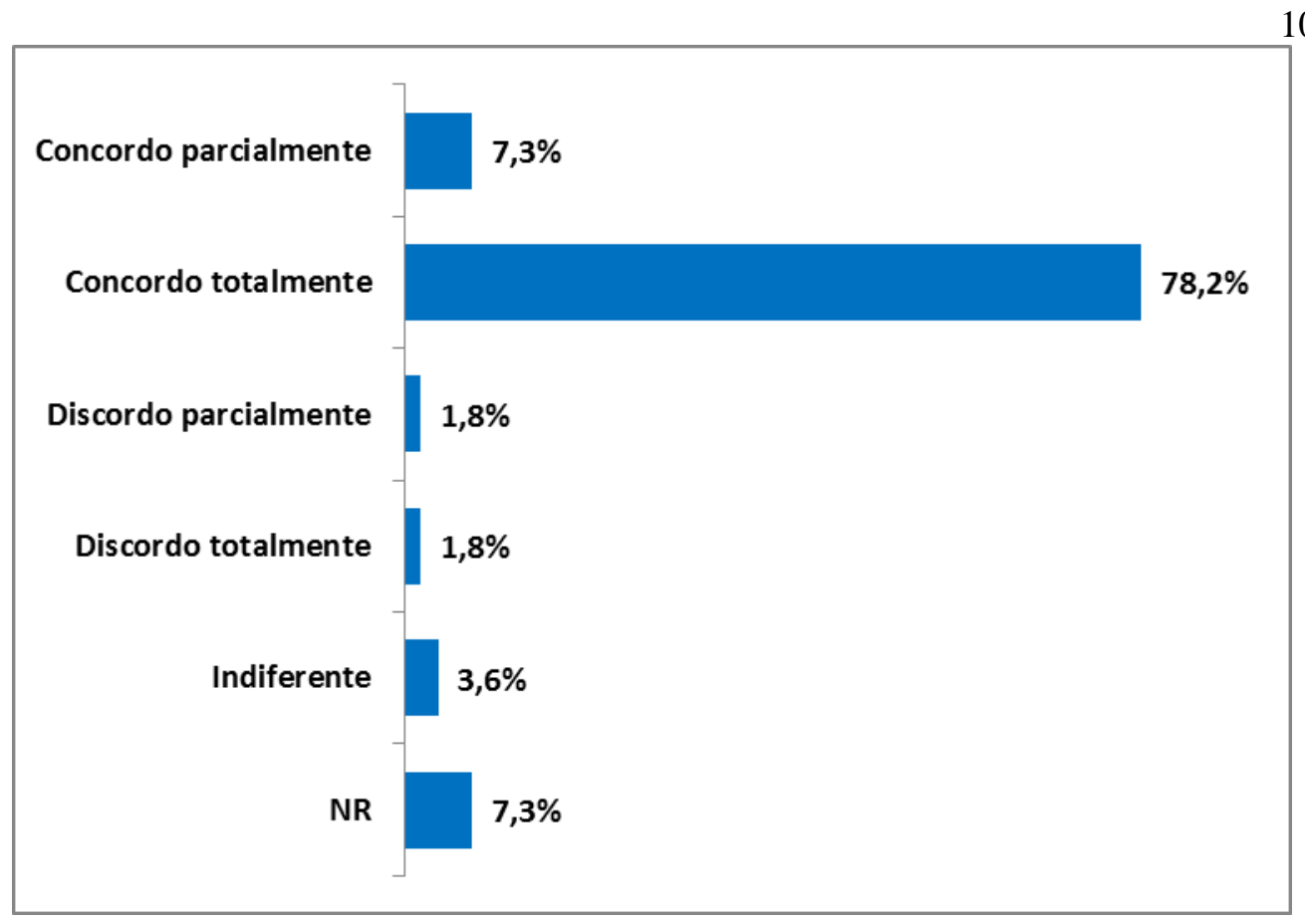

Gráfico 5 - Distribuição dos apenados em relação à percepção dos mesmos sobre a necessidade de respeito às mulheres.

$\mathrm{Na}$ afirmativa relativa à necessidade de respeito às mulheres, temse que $85,5 \%$ dos homens acreditam que é preciso respeitar as mulheres e apenas $3,6 \%$ acreditam que não seja preciso ter respeito em relação às mulheres. Esta informação pode parecer contraditória, ou partir do pressuposto que a prática de violência doméstica não é considerada um desrespeito contra a mulher. Para uma análise mais acurada é necessário

15 Uma importante contribuição para esta reflexão e a que será levantada a seguir é a de Jessé Souza. O autor utiliza as categorias teóricas de Bourdieu e de Charles Taylor para avaliar a importância jurídica e política do funcionamento da sociedade para a questão da percepção da dignidade, e da hierarquia valorativa que ela pressupõe em uma sociedade desigual como a compreender profundamente a representatividade do conceito de respeito para os apenados e o quanto ele expressa uma hierarquia valorativa que ele nem tem consciência. ${ }^{15}$

\section{Os sentidos da violência de gênero}

Após a apresentação das principais categorias teóricas e dos dados, passaremos à conexão de sentido entre eles. Conforme já destacamos, a

brasileira. "O corpo é, enfim, o campo de forças de uma hierarquia não expressa - entre sexos, classes ou grupos de idade - contribuindo decisivamente para a naturalização da desigualdade em todas as suas dimensões". (Souza, 2013, p. 152) 
“dessubstancialização" da categoria violência de gênero permite uma reflexão mais multidimensional, a partir dos diferentes campos envolvidos. $\mathrm{Na}$ mesma linha Matos aponta que:

Ao pesquisador resta a tarefa contínua tanto de desconstruir as diferenças quanto de desnaturalizá-las; procurar desvendar o estabelecimento das hegemonias discutindo com rigor as questões de subordinação/dominação; adotar uma perspectiva de gênero relacional, posicional e situacional - lembrando que gênero não se refere unicamente a homens e mulheres e que as associações homem-masculino e mulherfeminino não são óbvias, devendose considerar as percepções sobre masculino e feminino como dependentes e constitutivas das relações culturais; procurando não essencializar sentimentos, posturas e modos de ser e viver de ambos os sexos. (Matos, 2002, p. 251)

A violência de gênero será agora analisada pela perspectiva de três campos: o social, o político e o jurídico.

$\mathrm{Na}$ perspectiva política surge a Lei Maria da Penha, que determina ao poder público o desenvolvimento de ações que visam a garantir os direitos humanos das mulheres no âmbito das relações domésticas e familiares, no sentido de resguardá-las de toda forma de negligência, discriminação, exploração, violência, crueldade e opressão. Surge em um contexto de políticas públicas dirigidas especificamente às mulheres como forma de diminuir a desigualdade de gênero no Brasil. Aqui o Direito como objetivo (Coutinho, 2013) no âmbito das políticas públicas.

$\mathrm{Na}$ perspectiva jurídica, a execução penal foi a principal decorrência da Lei Maria da Penha-. Foi a partir da execução da pena, oriunda dos fatos de violência doméstica ocorridos na sociedade, em especial, por aqueles levados ao conhecimento do Estado, por meio do Judiciário, que a pesquisa foi realizada no momento da execução da pena. Os dados apurados e apresentados no presente trabalho são de grande relevância para tentar entender a aplicação da culpabilidade e da pena, na percepção do apenado em comparação com o Direito Penal dogmático e mesmo da perspectiva do Estado e do juiz.

No entanto, essas medidas dependem do envolvimento de diferentes atores nos âmbitos do governo e da sociedade, bem como da introdução de conhecimentos específicos sobre a temática e tecnologias diferenciadas para profissionais que atuam diretamente na atenção à saúde. Essas transformações devem ser integradas a outras iniciativas, possibilitando, assim, a formação de redes de atenção para mulheres em situação de violência, uma vez que problemas complexos exigem soluções multifacetadas. (Fonseca; Guedes 2011, p. 28) 
Neste sentido a Dogmática

Penal não parece considerar as peculiaridades da violência de gênero.

Por isso o papel da Criminologia.

Ensinar Criminologias, nesta perspectiva, é concorrer para a formação de uma consciência jurídica crítica e responsável, capaz de transgredir as fronteiras, sempre generosas, do sono dogmático, da zona de conforto do penalismo adormecido na labuta técnico-jurídica; capaz de inventar novos caminhos para o enfrentamento das violências (individual, institucional e estrutural) e esse talvez seja o melhor tributo que possam prestar ao Ensino e à formação profissional cidadã. (Andrade, 2013, p. 183)

Claro que a Dogmática Penal não é o mecanismo para fazer política social, e "as mulheres não podem buscar a sua emancipação através do poder punitivo e sua carga simbólica" (Mello, 2010, p. 941). A própria mulher, foi vítima da carga simbólica do Direito Penal, "quando só poderia ser considerada vítima de determinados crimes quando fosse honesta, ou seja, quando se portasse da maneira adequada na visão masculina” (Mello, 2010, p.

$16 \mathrm{Na}$ verdade esta constatação existe para a própria redução da criminalidade, conforme aponta Azevedo: "A resposta penal se converte em resposta simbólica oferecida pelo Estado em face das demandas de segurança e penalização da sociedade, expressas pela mídia, sem relação
941) Mas a criminalização e o punitivismo por si só não irão alterar o quadro da violência de gênero atual. ${ }^{16}$

Por fim, a perspectiva social. Aqui, "por sua característica basicamente relacional, a categoria gênero procura destacar que a construção do feminino e masculino define-se um em função do outro, uma vez que se constituíram social, cultural e historicamente em um tempo, espaço e cultura determinados" (Matos, 2002, p. 244).

Assim, segundo Bourdieu (2002), a lógica da relação de dominação chega a impor e inculcar nos homens e nas próprias mulheres todas as propriedades negativas que a ideologia machista dominante atribui à natureza feminina. A visão patriarcal é continuamente confirmada e legitimada pelas próprias práticas que determina, fazendo com que as mulheres incorporem o preconceito desfavorável contra o feminino. Sendo assim, a dominação masculina tem todas as condições favoráveis para seu pleno

direta com a verificação de sua eficácia instrumental como meio de prevenção ao delito. $\mathrm{O}$ direito penal se converte em recurso público e gestão de condutas utilizado contingencialmente e não em instrumento subsidiário de proteção de interesses ou bens jurídicos".(2005, p. 236) 
exercício, uma vez que a primazia masculina se afirma e é incorporada por toda a estrutura social. (Fonseca; Guedes, 2011)

As mudanças na legislação e a implementação das políticas públicas relativas à violência são necessárias e fundamentais, porém, isoladamente, não significam a garantia de efetividade para o enfrentamento do problema, uma vez que a violência contra a mulher é permeada por uma complexa trama de fatores sociais, culturais e ideológicos que dificultam e até mesmo impedem a efetiva vigência dos direitos humanos. (Fonseca; Guedes, 2011, p. 30)

Isto porque as desigualdades de gênero são estruturantes da sociedade brasileira, ou seja, os papéis sociais de homens e mulheres foram sendo construídos ao longo da história, constituindo relações sociais hierárquicas e desiguais, as mencionadas “dissimetrias de poder".

\section{Conclusão}

Diante dos dados apresentados neste artigo e a conexão com as categorias teóricas, é possível concluir a relevância e o desafio que representa o olhar sociojurídico para a dogmática penal diante da contínua naturalização da violência contra a mulher apesar da legislação e da onda punitivista da dogmática.

A explicação para a persistência da violência reside nas "dissimetrias de poder", e na necessidade de compreensão de como a sociedade se "inscreve" em cada indivíduo e se reproduz a partir dele (Souza, 2013).

A proposta de análise dos dados sobre a percepção do apenado acerca do respeito visou responder esta inquietação a partir da hierarquia valorativa presente nas relações de gênero, nos "sujeitos, mesmo que eles não tenham consciência de que agem da forma como agem e que avaliam do modo como avaliam"(Souza, 2013, p. 150).

Por isso também o desafio de observar a legislação e seus fins (erradicar a violência contra a mulher) na sua dinâmica e complexidade, pois "o direito não apenas é elemento constitutivo das políticas públicas, mas também componente-chave na sua implementação" (COUTINHO, 2013, p. 200).

A desnaturalização da dissimetria de poder nas práticas sociais e nas relações de gênero é o desafio para a Dogmática Penal. O olhar sociojurídico e a criminologia podem ajudar a construir estratégias para que a igualdade 
de gênero seja efetivamente internalizada nas práticas sociais, na dimensão da vida cotidiana. (Souza, 2013)

\section{Referências bibliográficas}

ANDRADE, Vera Regina Pereira de. Por que a criminologia (e qual criminologia) é importante no Ensino Jurídico? UNISUL de fato e de direito. Ano III, n. 6, jan/jun, p. 179-183, 2013.

AZEVEDO, Rodrigo Ghiringhelli. Criminalidade e justiça penal na América Latina. Sociologias. Porto Alegre, Ano 7, n. 13, jan/jun 2005, p. 212-241.

BOURDIEU, Pierre. A dominação masculina. 2 ed. Rio de Janeiro: Bertrand, 2002.

O Poder Simbólico. Rio de Janeiro: Bertrand, 1989.

Coisas Ditas. São Paulo:

Brasiliense, 1990.

Razões Práticas. Campinas:

Papirus, 1996.

Questões de Sociologia. Fim de

Século: Lisboa, 2003.

COUTINHO, Diogo R. O direito nas políticas públicas. In: MARQUES, Eduardo; FARIA, Carlos Aurélio Pimenta de (orgs) A política pública como campo multidisciplinar. São Paulo: UNESP, 2013, p. 181-200.

FONSECA, Rosa Maria Godoy Serpa da; GUEDES, Rebeca Nunes. Versão ampliada do trabalho apresentado na mesa redonda "Violência doméstica: um olhar de gênero" na 63 Reunião Anual da SBPC, Goiânia, 14 de julho de 2011.

GARCIA, Margarida. Novos horizontes epistemológicos para a pesquisa empírica em Direito: “descentrar" o sujeito, "entrevistar" o sistema e dessubstancializar as categorias jurídicas. Revista de Estudos Empíricos em Direito. V. 1, n. 1, jan 2014, p. 182-209.

MATOS, Maria Izilda S. de. Da invisibilidade ao gênero: percursos e possibilidades nas ciências sociais contemporâneas. Margem. São Paulo, n. 15, Jun. 2002 p. 237-252.

MELLO, Marília Montenegro Pessoa de. A Lei Maria da Penha e a força simbólica da "nova criminalização" da violência doméstica contra a mulher. Anais do XIX Encontro Nacional do CONPEDI. Fortaleza, 2010, p. 936-950. PIMENTEL, Silvia; SCHRITZMEYER, Ana Lucia Pastore; PANDJIARJIAN, Valéria. Estupro: direitos humanos, gênero e justiça. Revista USP, n. 37, p. 58-69, março/maio 1998. 
RIBEIRO, Dominique de Paula.

Violência contra a mulher: aspectos gerais e questões práticas da Lei $\mathrm{n}$. 11.340/2006. Brasília: Gazeta Jurídica, 2013.

SILBEY, Susan S. Making a Place for Cultural Analyses of Law. 17 Law \& Soc. Inquiry 39, 1992.

SILBEY, Susan S; EWICK, Patricia.

Conformity, Contestation, and

Resistance: An Account of Legal

Consciousness. 26 New Eng. L. Rev. 73, 1992.

SOUZA, Jessé. O que é a "dignidade humana"? Acerca da importância dos direitos sociais em uma sociedade desigual. In: TOLEDO, Cláudia (org). Direitos sociais em debate. Rio de Janeiro: Elsevier, 2013, p. 127-157.

VILLEGAS, Maurício García.

Sociología y crítica del derecho.

México: Fontamara, 2010 